\title{
Resumen del conversatorio sobre Geopolítica: Los casos de Medio Oriente y Ucrania con el Dr. Augusto Zamora. Ex embajador de Nicaragua en España
}

A inicios de septiembre del año en curso, el Dr. Augusto Zamora, ex-embajador de Nicaragua en España, conversó con docentes y estudiantes de nuestra facultad, sobre temas de carácter internacional y que hoy están siendo focos de tensión. Se refirió a la compleja problemática que hoy vive el Medio Oriente y las diferentes posiciones políticas, religiosas, económicas y étnicas, donde cada país de la zona, defiende sus intereses que se remonta siglos atrás, también se refirió a los casos de Crimea y Ucrania, a los países emergentes, América Latina y desde luego a Estados Unidos como potencia generadora de conflictos en el mundo. Hizo alusión a la geografía, como disciplina de enorme importancia en la actualidad, señalando a propósito de lo geográfico, que el continente americano, tenía una situación muy particular dado que era el más aislado del mundo y que eso tenía sus consecuencias en la realidad geopolítica actual.

En cuanto al Medio Oriente, empezó historiando que en el año 632, el profeta Mahoma, máximo líder de la religión musulmana, proclamó a su yerno Alí como su sucesor espiritual y político, con lo cual comenzó una disputa entre dos vertientes que desde ese momento están divididas: los chiitas y los sunitas. Los primeros creían que el sucesor debía ser descendiente directo de Mahoma, mientras que para los segundos interesaba una persona justa que no necesariamente debía tener el linaje de su líder. Es importante señalar, que entre los siglos VIII y XIV, los árabes controlaban el mediterráneo y tenían una posición muy visible en cuanto al desarrollo de la ciencia.

Irak cuyo gobierno es chiita, enfrenta la resistencia sunita y sobre todo la más radical que es el Estado Islámico, que reclama el regreso al Islam pero con posiciones radicales, a esto se agrega dentro de Irak, los Kurdos. En Iraq hay alrededor de cuatro millones de kurdos, los que no tienen un interés religioso, sino que históricamente buscan su independencia y la conformación de un Estado, el Kurdistán, que abarca regiones de Iraq, Turquía, Irán, Siria y Armenia. En el conflicto actual, los kurdos defienden Kurdistán y sus fronteras, las cuales han estado en peligro ante los ataques de ISIS (Estado Islámico) en ciudades fronterizas. En algunas de estas urbes, el ejército iraquí bajó las armas y huyó, por lo que los peshmerga - milicia kurda- ha tomado control de estas zonas, principalmente Kirkuk, uno de los principales centros petrolíferos. Los Kurdos también viven en Irán y Siria.

En cuanto a Siria, que son mayoría Chiita apoya al actual gobierno de Irak en contra del Estado Islámico, pero también Siria es visto como una amenaza por Estados Unidos en la región y es acusado de madurar cianuro para armas nucleares y amenazar sobre todo a Israel quien representa los intereses de Norteamérica en la zona. Los Sirios enfrentan también las amenazas del Estado Islámico, son religiosamente Alauditas tienen una visión particular de los fundamentos del islam, por lo que muchos musulmanes los consideran herejes, la gobernante familia al Asad en Siria pertenece a esta rama.

1 UNAN-Managua/FAREM-Estelí Correo electrónico: edulopez26@yahoo.es 
Arabia Saudita, también representa los intereses de Estados Unidos y al contrario de Irán, Arabia Saudita tiene una población mayoritariamente sunita. Este país ha acusado a Al Maliki (Presidente de Irak) de llevar a cabo políticas sectarias y excluyentes en detrimento de la comunidad sunita en Iraq. Malaki considera que Arabia Saudita en quien brinda apoyo moral y financiero al Estado Islámico. Otro Estado que se cree apoya al Estado Islámico en Quatar, a Turquía se le considera como el corredor por donde fluyen las armas para los rebeldes islamitas, quienes como parte de sus acciones repudiables desde todo punto de vista, han decapitado a periodistas de Estados Unidos, Reino Unido y Francia.

El Dr. Zamora indicó que la problemática del Medio Oriente, cuenta con el respaldo de Rusia y China, potencias mundiales que están viviendo coyunturas muy particulares, la primera, está asistiendo a un resurgimiento, después de la caída de la URSS en 1989 y en el marco de ese resurgimiento, esta enfrentada con la Unión Europea y Estados Unidos, siendo las causa de ese enfrentamiento, los territorios de Crimea y Ucrania, territorios de origen ruso que en el contexto de la federación rusa que surge con la revolución bolchevique de 1917, fueron delimitados como el caso de Ucrania por Lenin en 1921 y Crimea que paso a ser parte de Ucrania en 1954, decisión tomada por Nikita Kruschev, primer Secretario del Partido Comunista de la URSS ( PCUS) . La anexión actual de Crimea a Rusia decidida por Vladimir Putin y la compleja situación de Ucrania, ha llevado a tensar las relaciones de occidente con Rusia, donde Estados Unidos que encabeza las amenazas, tiene como punta de lanza a la OTAN (Organización del Tratado del atlántico Norte) para mantener el asedio contra Rusia que incluye el aspecto económico.

En el caso de China, Zamora indico que este país será en las próximas décadas, más temprano que tarde, la primera potencia del mundo, que ya supera a Estados Unidos en muchos renglones como es el caso de le energía, no obstante, tiene todavía limitaciones como la pobreza y en el campo tecnológico. Expreso que entre ambas potencias hay una relación simbiótica.

También se refirió al surgimiento de potencias regionales como Rusia, Irán, India, Brasil, etc. las que están configurando un nuevo mapa geopolítico y económico mundial y que ya pesan en el concierto internacional en aspectos de enorme relevancia como el petróleo, materias primas, el comercio mundial, industria, etc. Además hay que considerar dijo, el potencial que tiene Asia en términos económicos y su presencia en los mercados mundiales.

En cuanto a América Latina, indicó que es un subcontinente con muchas ventas comparativas y sobre todo en materia de biodiversidad tan fundamental en este siglo XXI que es amenazado por la globalización.

Finalmente señalo que Estados Unidos sigue siendo el imperio desestabilizador del planeta, para lo cual ha organizado coaliciones como es el caso de Afganistán, conflicto militar que duró 14 años, dos coaliciones contra Irak, otra para la destrucción de Libia y la actual en el medio oriente. 